\title{
Research Paper: Effectiveness of Self-management Interventions Based on Cognitive-behavioral Group Therapy on Life-style Among Adults With Metabolic Syndrome: A Randomized Clinical Trial
}

\author{
Ali Delshad Noghabi ${ }^{1}$ (D, Mohammad Hossein Bayazi $^{1^{*}}$ (D), Ali Reza Rajaei ${ }^{1}$ (D) \\ 1. Department of Psychology, Torbat-e Jam Branch, Islamic Azad University, Torbat-e Jam, Iran.
}

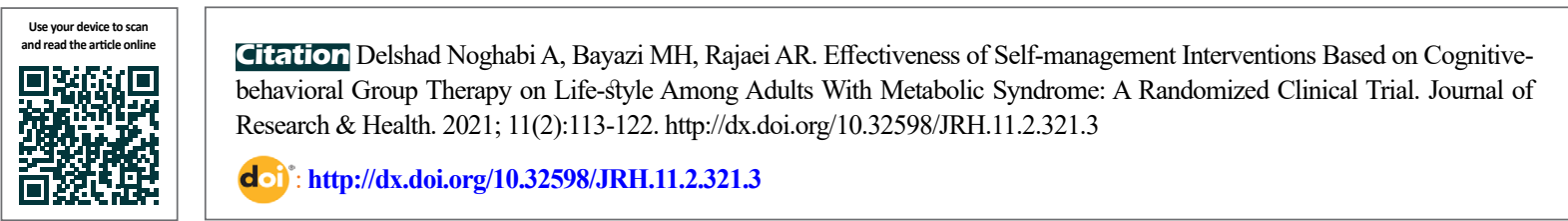

\section{(i) (5)}

Article info:

Received: 12 Dec 2020

Accepted: 02 Jan 2021

Publish: 01 Apr 2021

\section{Keywords:}

Self-management, Cognitivebehavioral therapy, LifeStyle, Metabolic syndrome

\section{A B S T RACT}

Background: Metabolic syndrome is an asymptomatic disorder and an important risk factor for cardiovascular disease and type 2 diabetes. Lifestyle modification and self-management of health-promoting behaviors are the most important actions to control metabolic syndrome. This study was done to investigate the effectiveness of self-management interventions based on group Cognitive-Behavioral Therapy (CBT) on lifestyle among adults with metabolic syndrome.

Methods: This research was a randomized clinical trial study. First, 80 adults with metabolic syndrome were selected using the convenience sampling method, and then, using the randomized blockchain method, they were divided into two groups of 40 people (intervention and control groups). Data collection using the Health Promotion Lifestyle Profile II Questionnaire (HPLP II) was performed in two stages before and three months after the intervention. Teaching selfmanagement interventions based on cognitive-behavioral therapy was done twice a week for eight 90-minute sessions. Data were analyzed using the Chi-square test, independent t-tests, and Analysis of Covariance (ANCOVA). A P-value less than 0.05 was considered significant.

Results: the results of ANCOVA showed that self-management intervention based on group CBT had a significant effect on the dimensions of lifestyle, including exercise and physical activity with an effect size of 0.51 , nutrition with 0.49 , health responsibility with 0.39 , and stress management with $0.32(\mathrm{P}<0.05)$, but it did not significantly affect the two dimensions of selfactualization and spiritual growth (effect size $=0.003, \mathrm{P}=0.669)$ and interpersonal relationships (effect size $=0.029, \mathrm{P}=0.151$ ).

Conclusion: Self-management interventions based on group CBT can improve lifestyle and some dimensions in adults with metabolic syndrome. Identifying people with metabolic syndrome and performing effective interventions with the active participation of the individual through self-management based on cognitive-behavioral therapy seem necessary.

\section{${ }^{*}$ Corresponding Author:}

Mohammad Hossein Bayazi, PhD.

Address: Department of Psychology, Torbat Jam Branch, Islamic Azad University, Torbat Jam, Iran.

Phone: +98 (915) 1679599

E-mail: bayazi123@gmail.com 


\section{Introduction}

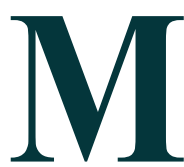

etabolic Syndrome (MetS) is defined as a set of metabolic disorders based on the criteria of the Adult Treatment Panel (ATP III) released by the National Cholesterol Education Program despite at least 3 criteria of abdominal obesity, high Triglyceride (TG), low High-Density Lipoprotein (HDL), high blood pressure, and high blood sugar [1].

The prevalence of MetS in Iran is about 33\%, which is far higher than the United States and Europe (25\%) and many Asian countries [2]. According to the ATP III definition, metabolic syndrome is present when at least three of the following risk factors out of five factors are present: 1. Abdominal obesity (in terms of the waist): Waist Circumference (WC) equal to or more than $102 \mathrm{~cm}$ (40 inches) in men and equal to or more than $88 \mathrm{~cm}$ (35 inches) in women, according to the guidelines of the Nutrition Improvement Office of the Ministry of Health and Medical Education in Iran; WC equal to or more than 90 $\mathrm{cm}$ is recommended as abdominal obesity. 2 . TG equal to or more than $150 \mathrm{mg} / \mathrm{dl}$ or specific treatment, 3. HDLcholesterol less than $40 \mathrm{mg} / \mathrm{dl}$ in men and less than 50 $\mathrm{mg} / \mathrm{dl}$ in women or its specific treatment, 4. Hypertension (diastolic blood pressure equal to or greater than 85 $\mathrm{mm} \mathrm{Hg}$ and systolic blood pressure equal to or greater than $130 \mathrm{~mm} \mathrm{Hg}$ ) or taking antihypertensive drugs, and 5. Fasting Blood Sugar (FBS) equal to or greater than $100 \mathrm{mg} / \mathrm{dl}$ or taking anti-diabetic drugs [3].

The treatment of MetS is actually the treatment of its components that include hypertension, hyperglycemia, dyslipidemia, and obesity. The first line of treatment for MetS is lifestyle modification, i.e. having a healthy diet and regular physical activity to lose weight [4]. Wrong eating habits, inactivity, stress, race, and genetic factors are the reasons for the high prevalence of MetS [5]. People with MetS have been found to die two to three times more often from cardiovascular disease [6]. Also, the prevalence of Cardiovascular Disease (CVD), Myocardial Infarction (MI), and stroke (CVA) in patients with MetS were three times higher than obese people without this disorder [7]. Clinically, MetS is an important risk factor for progression to non-communicable and chronic diseases, such as type 2 diabetes and coronary artery disease. Therefore, the clinical concept of diagnosing MetS mainly includes identifying patients who need to change their lifestyle with an emphasis on weight loss, increased physical activity, and control of blood pressure and blood lipids [3].
Health requires the promotion of a healthy lifestyle. Lifestyle is highly important because it affects the quality of life and disease prevention. To maintain and promote health, lifestyle modification and improvement are essential [8]. Many health problems, such as obesity, CVD, cancer, and addiction, which are common in most countries today, especially in developing countries, are associated with lifestyle changes. Improper lifestyle is also one of the effective factors in the incidence of chronic diseases, such as diabetes, colon cancer, hypertension, chronic obstructive pulmonary disease, liver cirrhosis, gastric ulcer, AIDS, and CVD [9]. Non-communicable diseases are especially closely related to lifestyle; in other words, lifestyle is one of the important determining factors in a person's health and illness [10]. On the other hand, health-promoting behavior as a key issue in the concept of health promotion has attracted the attention of researchers for the development of health programs [11].

Self-management of the responsibility and participation of people with chronic diseases in informed clinical decisions, cooperation with people in charge of their health, minimizing the impact of the disease on functional status, emotions, and interpersonal communication, as well as monitoring and management of the signs and symptoms of the disease, are used to minimize the frequency and consequences of exacerbations of the disease [12]. Self-management education is one of the essential points in caring for chronic conditions. Self-management has a positive effect on knowledge, repetition, accuracy, and precision of self-control of physical activity, diet behaviors, stress management, and controlling blood sugar, fat, blood pressure, and weight. Knowledge alone does not directly lead to behavior change or selfcontrol in chronic diseases, knowledge enhancement has been identified as a prerequisite for increasing self-efficacy as well as behavior change [13]. Self-management is defined as the ability of individuals to manage the symptoms, treatment, and physical, psychological, and social consequences of the disease and lifestyle changes in order to adapt to the chronic situation [14].

The results of various studies have shown that selfmanagement of chronic diseases can improve the level of efficiency, increase knowledge, increase self-care behaviors, improve health status, reduce visits to medical centers, and improve quality of life [15-17]. However, in another study, the implementation of a self-management program had no effect on improving self-efficacy and self-care of chronic patients [18]. In another study, the results showed that Cognitive-Behavioral Therapy (CBT) could be used to increase adherence to treatment, illness perception, and quality of life in patients with 
chronic medical conditions [19]. Self-management training encourages the patient to actively participate in selfcare and increase responsibility in controlling symptoms and complications, and helps the individual to maintain a great deal of independence, and increases the individual's efficiency. This reduces patients' dependence on medical staff and other family members, as well as treatment costs, and allows the individual to work and live in the workplace, community, and family [20].

Regarding self-care for chronic diseases, recognizing the symptoms and methods of treating the disease, recognizing negative thoughts and spontaneous or automatic thoughts is necessary, and then educating and encouraging patients to observe healthy behaviors to improve the disease or chronic conditions should be done; thus, one of the most widely used psychological therapy is CBT [21]. CBT is short-term psychotherapy that psychotherapists use to educate people and change their feelings and behaviors by changing their thought patterns and beliefs. CBT is the type of thinking and thought patterns, our knowledge about the environment and ourselves, our personal interpretation of life events, and our behaviors and feelings. In general, CBT is the way we think and how we feel; thus, our behaviors are shaped according to the same thoughts and feelings. The focus of CBT is on the impact of a person's beliefs, thoughts, and attitudes on his or her feelings and behaviors, and the goal is to teach clients how to actively face and overcome various problems or events throughout their lives [22].

A chronic illness diagnosis often comes with high levels of uncertainty, lifestyle changes, and treatments that are costly and time-consuming. Given these stressors, it is not surprising that individuals living with chronic illness are at significantly higher risk of struggling with anxiety, depression, adjustment disorders, and other mental health concerns compared with those living without chronic illnesses. After the diagnosis, individuals are often asked to make radical lifestyle changes, including changes that may affect individuals socially, professionally, and romantically [23]. Chronic medical problems are often associated with some types of psychological problems, such as mood disorder and fatigue, for which CBT has proven to be effective. The importance of adopting an active self-management approach and the need for patients to establish collaborative relationships with health care staff make a cognitive therapy framework particularly suited to address the problems associated with chronic disease [24]. Therefore, this study was conducted to determine the effectiveness of self-management interventions based on CBT in adults with MetS.

\section{Methods}

This study is a randomized clinical trial with clinical trial registration number IRCT20200507047343N1. The study population was adults above 30 years old who were referred to three comprehensive health service centers in Gonabad in 2019. Before sampling, the code of ethics was obtained (IR.GMU.REC.1398.160). Adults who met the inclusion criteria and wanted to participate in the study were selected and after providing explanations about the study and its objectives and methodology, the subjects were assured of the confidentiality of information, and they signed the informed written consent to participate in the study. The following inclusion criteria were considered: the age of between 30 and 70 years, completing the informed consent form, having MetS based on the criteria defined in the definition of MetS (based on the results of blood glucose tests and blood lipid profile in the last three months and blood pressure and WC), no history of known mental disorders, such as depression and dementia based on patient care record, having the ability to self-care, and having a minimum literacy rate. Exclusion criteria included unwillingness to continue cooperation, being absent for more than two training sessions, the need to change the medical treatment plan, and hospitalization during the study.

First, using a connivance sampling method, from three comprehensive health service centers in Gonabad and from 290 adults over 30 years of age with active care records, 88 people who were eligible for inclusion in the study were randomly selected and divided into the intervention (44 people) in the control groups (44 people). During the study, four cases from each group left the study, and finally, each group included 40 people. Random allocation of the research sample to the intervention and control groups was performed based on quadruple permuted-block randomization so that in each block, two allocations were allocated to the intervention group and two allocations to the control group. In the intervention group, self-management based on group CBT training on MetS was done based on the Guide to Therapeutic Strategies in MetS and Lifestyle Interventions to Reduce MetS and Heart Disease developed by the Oxford University [25]. The intervention sessions were held in eight 90-minute sessions twice a week (Table 1).

In the first session, a pre-test was taken from each group. All sessions started with a review of the topics and presentation of homework by the samples, followed by providing explanations about the session discussion, summarizing the discussion, answering questions, and presenting homework for the session. The session was 
Table 1. Sessions of Self-management Interventions based on group cognitive behavioral therapy

\begin{tabular}{|c|c|c|}
\hline Session & Subject & Description \\
\hline 1 & $\begin{array}{l}\text { Introduction, pre-test, meta- } \\
\text { bolic syndrome }\end{array}$ & $\begin{array}{l}\text { Introduction, statement of goals, time and manner of meetings, emphasis on the confi- } \\
\text { dentiality of information, pre-test, description of metabolic syndrome, its causes, symp- } \\
\text { toms, prevention methods, diagnostic methods, and complications in simple language }\end{array}$ \\
\hline 2 & Self-care and self-management & $\begin{array}{l}\text { Self-care and self-management were taught in maintaining and promoting individual } \\
\text { health, problem-solving skills techniques with the help of participants, and practical ex- } \\
\text { amples. At the end of the session, participants were asked to bring some practical ex- } \\
\text { amples to the next session. }\end{array}$ \\
\hline 3 & Cognitive behavioral therapy & $\begin{array}{l}\text { Familiarity with cognitive-behavioral therapy, the relationship between thoughts, feel- } \\
\text { ings, and behaviors with practical examples, types of cognitive errors, central spontane- } \\
\text { ous thoughts, negative spontaneous thoughts, strategies to combat cognitive distortions, } \\
\text { teaching profit, and loss techniques and its practice in the session, and summarizing the } \\
\text { contents and assigning the task for the next session }\end{array}$ \\
\hline 4 & Stress and anxiety & $\begin{array}{l}\text { Familiarity with anxiety, stress, worries, and fears, training coping skills with anxiety and } \\
\text { stress and including deep breathing exercises and relaxation techniques in theory and } \\
\text { practice }\end{array}$ \\
\hline 5 & $\begin{array}{l}\text { Proper nutrition and adherence } \\
\text { to treatment instructions }\end{array}$ & $\begin{array}{l}\text { Familiarity with the food pyramid, nutrition in people with metabolic syndrome and ap- } \\
\text { propriate or inappropriate foods, how to properly use medications and adherence to the } \\
\text { correct use of medications and foods, and completing a checklist of foods and medica- } \\
\text { tions until the next session }\end{array}$ \\
\hline 6 & Exercise and mobility & $\begin{array}{l}\text { The importance of mobility in maintaining health, aerobic and anaerobic exercises, and } \\
\text { walking and its principles. At the end of the session, participants were asked to fill a mo- } \\
\text { bility and exercise checklist for the next session and bring it in the next session. }\end{array}$ \\
\hline 7 & $\begin{array}{l}\text { Health self-assessment, Obe- } \\
\text { sity, and its control }\end{array}$ & $\begin{array}{l}\text { Methods of health assessment, assignment evaluation and intervals, interpretation of } \\
\text { the tests in simple language, anthropometric methods and correct measurement of } \\
\text { height and weight and calculation of BMI, obesity and its complications, cognitive-behav- } \\
\text { ioral interventions for obesity control }\end{array}$ \\
\hline 8 & $\begin{array}{l}\text { Prevention of relapse and } \\
\text { behavioral methods of health } \\
\text { promotion }\end{array}$ & $\begin{array}{l}\text { Strategies for preventing the relapse of unhealthy behaviors, self-control, self-encourage- } \\
\text { ment, self-punishment, self-talk, and encouragement by others by giving examples, and } \\
\text { review of the instructed contents, and summarizing what has been learned during the } 8\end{array}$ \\
\hline Post-tes & $\begin{array}{l}\text { Completion of the question- } \\
\text { naires three months after the } \\
\text { end of the intervention }\end{array}$ & $\begin{array}{l}\text { Inviting the samples in the intervention and control group to complete questionnaires } \\
\text { and holding a training session for the control group to teach the contents provided for the } \\
\text { intervention group, distribution of educational pamphlets, and appreciation }\end{array}$ \\
\hline
\end{tabular}

then summarized as an educational pamphlet. In addition, the researcher's contact number was provided to them in the first session to guide them in doing their homework. The control group received only routine care and training, such as face-to-face training, providing related books and pamphlets, and lectures. Three months after the end of the intervention, by inviting the samples in the intervention and control groups, the post-test was performed by re-completing the questionnaires. Data collection tools included the Demographic Characteristics Questionnaire and Walker Health-Promoting Lifestyle Profile II Questionnaire (HPLP-II).
The Walker HPLP- II Questionnaire is a native tool for measuring health-promoting behaviors that was developed by Walker et al. in 1987. HPLP-II measures how frequently the participants are engaged in 52 healthpromoting behaviors. The items are categorized into six sub-scales: Nutrition $(\mathrm{N}=9)$ assesses meal patterns and deals with the choice of a good and balanced diet, Physical Activity $(\mathrm{PA}=8)$ measures regular exercise patterns and recreational activities, Stress Management $(\mathrm{SM}=8)$ quantifies the ability to cope with stress and focuses on using relaxation methods to control stress, Health Responsibility $(\mathrm{HR}=9)$ measures the individual's general health concerns, Spiritual Growth and self-actualization $(\mathrm{SG}=9)$ refers to the process of becoming conscious of 
existence and a force beyond the self, and Interpersonal Relations ( $I R=9)$ assesses a sense of intimacy and deals with meaningful relationships. This tool measures the participant's self-reported health promoting behaviors, with higher scores indicating more frequent health-promoting behaviors or well-being habits on a 4-point Likert scale, with the following choices: $1=$ never, $2=$ some times, $3=$ often, or $4=$ routinely [26]. Mohammadi Zeidi et al. in a study entitled "Validity and Reliability of the Persian version of the Health Promoting Lifestyle Questionnaire" obtained the Cronbach's alpha coefficient of 0.82 for the whole questionnaire and 0.64 to 0.91 for its components [27].

In this study, SPSS V. 20 software was used to analyze the data. First, the mean, standard deviation, and frequency of data were determined using descriptive statistics. Then, the independent t-test and Chi-square test were used to compare demographic variables in both groups. To analyze the independent variables, first, the normality of data in the two groups was also evaluated using the Kolmogorov-Smirnov test, and the homogeneity of variances was examined. To evaluate the effect of the intervention on lifestyle dimensions by removing the pre-test and effect of post-test scores, the Univariate Analysis of Covariance (ANCOVA) was used. $\mathrm{P}<0.05$ was considered significant.

\section{Results}

According to the results, the mean age of the subjects in the intervention group was $49.37 \pm 10.37$ years and in the control group was $48.50 \pm 9.89$ years. The majority of participants were married, employed, and had a bachelor's degree or lower levels. Also, 55\% of the intervention group and $52.5 \%$ of the control group were women. No significant difference between the two groups in terms of relative frequency and mean data and the two groups were homogeneous $(\mathrm{P}<0.05)$. Due to the normality of the scores lifestyle and its dimensions in the pre-test and post-test and according to Table 2, there was no significant difference between the average lifestyle scores and its dimensions in the pre-test stage, but in the stage post-test, except for two dimensions of self-actualization and spiritual growth and interpersonal relationships, in other dimensions, including nutrition, exercise, and physical activity, stress management, health responsibility, and overall lifestyle, there was a significant dif-

Table 2. Mean scores of lifestyle and its dimensions in the two groups in the Pre-test and Post-test stages

\begin{tabular}{|c|c|c|c|c|}
\hline \multirow{2}{*}{ Variables } & \multirow{2}{*}{ Test } & \multicolumn{2}{|c|}{ Mean $\pm S D$} & \multirow{2}{*}{ Sig. } \\
\hline & & Intervention Group & Control Group & \\
\hline \multirow{2}{*}{ Nutrition } & Pre-test & $15.28 \pm 2.10$ & $16.08 \pm 3.93$ & 0.26 \\
\hline & Post-test & $21.83 \pm 3.16$ & $17.20 \pm 4.17$ & $<0.001$ \\
\hline \multirow{2}{*}{ Physical activity } & Pre-test & $17.85 \pm 2.79$ & $17.98 \pm 4.48$ & 0.88 \\
\hline & Post-test & $23.40 \pm 2.96$ & $19.38 \pm 3.90$ & $<0.001$ \\
\hline \multirow{2}{*}{ Stress management } & Pre-test & $18.50 \pm 4.07$ & $18.10 \pm 4.09$ & 0.66 \\
\hline & Post-test & $21.95 \pm 4.17$ & $19.83 \pm 3.76$ & 0.02 \\
\hline \multirow{2}{*}{ Interpersonal relationships } & Pre-test & $18.18 \pm 3.78$ & $17.90 \pm 4.22$ & 0.76 \\
\hline & Post-test & $19.73 \pm 3.30$ & $18.98 \pm 3.57$ & 0.33 \\
\hline \multirow{2}{*}{ Health responsibility } & Pre-test & $15.90 \pm 3.28$ & $15.58 \pm 4.42$ & 0.64 \\
\hline & Post-test & $18.63 \pm 4 . .05$ & $16.08 \pm 3.64$ & $<0.001$ \\
\hline \multirow{2}{*}{ Self-actualization \& spiritual growth } & Pre-test & $17.50 \pm 3.56$ & $18.15 \pm 3.55$ & 0.41 \\
\hline & Post-test & $18.62 \pm 4.04$ & $19.08 \pm 3.64$ & 0.38 \\
\hline \multirow{2}{*}{ Lifestyle (total) } & Pre-test & $103.73 \pm 9.45$ & $105.78 \pm 11.39$ & 0.49 \\
\hline & Post-test & $123.9 .15 \pm 9.15$ & $107.70 \pm 9.58$ & $<0,001$ \\
\hline
\end{tabular}


Table 3. Analysis of Covariance (ANCOVA) to assess the effect of self-management interventions based on group cognitivebehavioral treatment on lifestyle dimensions in the intervention group

\begin{tabular}{|cccccccc}
\hline Variables & Sum of Squares & df & Mean Squares & F & Sig. & Effect Size \\
\hline Nutrition & 451.426 & 1 & 451.426 & 46.567 & $<0.001$ & 0.49 \\
\hline Physical activity & 471.038 & 1 & 471.038 & 53.352 & $<0.001$ & 0.51 \\
\hline Stress management & 262.700 & 1 & 262.700 & 33.227 & $<0.001$ & 0.32 \\
\hline Interpersonal relationship & 14.671 & 1 & 14.671 & 2.013 & 0.151 & 0.029 \\
\hline Health responsibility & 281.163 & 1 & 281.163 & 38.258 & 0.025 & 0.39 \\
\hline Self-actualization \& spiritual growth & 0.854 & 1 & 0.854 & 0.184 & 0.669 & $0 / 003$ \\
\hline
\end{tabular}

ference between the two groups and post-test scores of the intervention group were higher than the control group $(\mathrm{P}<0.05)$

Normal distribution of lifestyle dimensions scores and homogeneity of variances were assessed and confirmed using the Kuamogorov-Smirnov test and Leven's test, respectively. To evaluate the effect of self-management intervention based on group CBT in the intervention group the univariate ANCOVA was used (Table 3). According to the results of Table 3, self-management intervention based on group CBT had a significant effect on the dimensions of lifestyle, including exercise and physical activity dimension with an effect size of 0.51 , nutrition dimension with 0.49 , responsibility for health with 0.39 , and stress management with an effect size of 0.32 , but it did not have a significant effect on the two dimensions of self-actualization and spiritual growth and interpersonal relationships $(\mathrm{P}<0.05)$.

\section{Discussion}

The main purpose of this study was to determine the effect of self-management intervention based on group CBT on the lifestyle of adults with MetS. The results of testing the research hypothesis confirmed this hypothesis.

The use of lifestyle-enhancing programs had a positive effect on reducing CVD and improved quality of life in these patients [28]. In a study, Lu et al. examined three training methods, including self-learning, monthly training lectures, and monthly group workshops. The findings of this study showed that group workshops are the most effective educational methods in improving the knowledge of patients with hypertension and preventing long-term complications of hypertension [29].
In a meta-analysis study, Chodosh et al. examined chronic disease self-management programs in the elderly. The findings of this study showed that chronic disease self-management programs have a beneficial effect on some physiological outcomes of the diseases. For example, it controls blood sugar and blood pressure but has no effect on controlling the weight of diabetic patients. These interventions also improved the complications of arthritis [30]. Because using self-management of chronic diseases, adherence and commitment of the individual to perform protective behaviors can improve the symptoms and reduce complications caused by the disease; therefore, it increases the health-promoting behaviors of the individual.

The results of this study are in line with the results of the study by Moattari et al. entitled "The effect of selfmanagement on metabolic control indices of insulindependent diabetic patients" who suggested training and the use of self-management programs for the care of diabetic patients [31]. This study is also consistent with the results reported by Zareipour et al. who showed that educational intervention for lifestyle modification is effective in gaining knowledge and changing the attitude, and behavior to control blood pressure [32]. Regarding the difference between these two studies and the present study, it can be said that these two studies did not examine the lifestyle of individuals and only measured the indicators related to a particular disease. On the other hand, these interventions were not based on self-management and CBT and did not specify the extent of the effect of the interventions in the analysis of their data to allow an accurate comparison. This study was also consistent with the research by Tandon et al. [33] and Moradi et al. [34] but was not consistent with the Sekendiza et al. study [35]. The passive educational method was used in these studies, such as lecturing or using booklets and pamphlets or only in a specific dimension of lifestyle, 
such as physical activity was considered. The reason for the lack of significant differences in the post-test scores of the two dimensions of self-fulfillment and spiritual growth and interpersonal relationships was due to the fact that in the educational intervention program of the intervention group, there was no training on these two dimensions in the educational protocol.

Prevention and treatment of chronic disorders and diseases largely depend on the will of the individual to adopt self-management and self-care behaviors [36]. Self-care behaviors include a proper diet, exercising regularly, checking tests and clinical examinations at regular intervals, stress management, and abstaining from tobacco and alcohol [37]. Therefore, for the control of chronic diseases, organized education based on identifying the educational needs of clients is an as important and appropriate treatment. Increasing patients' confidence in their ability to prevent disease is a key factor in active self-management of chronic disease prevention [38]. Cognitive therapy sessions are usually structured by a collaboratively agreed agenda. Active participation is encouraged by giving patients homework assignments to do at the intervals of the therapy sessions. Treatment involves the application of a range of cognitive and behavioral strategies designed to alter the factors that trigger, maintain, or exacerbate symptoms. The strategies are effective in helping patients to gain control over both psychological and physical symptoms [39].

Practical suggestions based on the results of this study include lifestyle modification training in adults through self-management interventions based on CBT that improve self-management of patients with MetS and improves its components. Therefore, it is suggested that in order to improve the self-management of patients with MetS on a larger scale, such interventions be considered and this method can be used in counseling and psychotherapy clinics and comprehensive health service centers. The cooperation of health psychologists and their presence in health centers can play an important role in the prevention and control of chronic diseases. It is suggested to conduct cohort and prospective research on the role of various interventions in the process of developing MetS in the population covered by medical universities and examining the predictors of MetS in society.

\section{Conclusion}

According to the results of this study, self-management interventions based on CBT can improve health-promoting lifestyles and some aspects of it in adults with MetS. Due to the progressive prevalence of MetS and its role as a set of risk factors in the development and spread of chronic diseases, especially diabetes and CVD, which is caused by inappropriate nutrition, inactivity, stress, obesity, and other factors related to lifestyle, people's lives can be improved by identifying people with MetS and performing effective interventions, through the active participation of people with self-management interventions based on CBT. In this intervention, obstacles and dysfunctional patterns of healthy behavior of individuals are identified by self-control and using problem-solving methods and positive changes are made in the lifestyle of adults with MetS.

\section{Ethical Considerations}

\section{Compliance with ethical guidelines}

This study was approved by the Ethics Committee of the University of Islamic Azad University, Torbat-e Jam Branch, (Code: IR.GMU.REC.1398.160.).

\section{Funding}

This article is taken from the $\mathrm{PhD}$. dissertation at the Department of Psychology, Torbat-e Jam Branch, Islamic Azad University, Torbat-e Jam.

\section{Authors' contributions}

All authors contributed to preparing this article.

\section{Conflict of interest}

The authors declared no conflict of interests.

\section{Acknowledgments}

The authors would like to thank the Vice Chancellor of the Islamic Azad University, Torbat-e Jam Branch.

\section{References}

[1] Huang PL. A comprehensive definition for metabolic syndrome. Dis Model Mech. 2009; 2:231-7. [DOI:10.1242/ dmm.001180] [PMID] [PMCID]

[2] Azizi F, Salehi P, Etemadi A, Zahedi-Asl S. Prevalence of metabolic syndrome in an urban population: Tehran lipid and glucose study. Diabetes Res Clin Pract. 2003; 61(1):29 37. [DOI:10.1016/S0168-8227(03)00066-4]

[3] Grundy SM, Cleeman JI, Daniels SR, Donato KA, Eckel RH, Franklin BA, et al. Diagnosis and management of the metabolic syndrome: An American Heart Association/Na- 
tional Heart, Lung, and Blood Institute scientific statement Circulation. 2005; 112(17):2735-52. [DOI:10.1161/CIRCULATIONAHA.105.169405] [PMID]

[4] Daneshpour MS, Sedaghatikhayat B, Hedayati M, Azizi F. From genome to gene: A review of genes and genetic variations to be associated with metabolic syndrome. Iran J Diabetes Metabol. 2015; 14(4):225-34. [DOI:10.1530/endoabs.37.EP606]

[5] Garaulet M, Madrid JA. Chronobiology, genetics and metabolic syndrome. Curr Opinion Lipidol. 2009; 20(2):127-34. [DOI:10.1097/MOL.0b013e3283292399] [PMID]

[6] Ford ES. Risks for all-cause mortality, cardiovascular disease, and diabetes associated with the metabolic syndrome: A summary of the evidence. Diabetes Care. 2005; 28(7):1769-78. [DOI:10.2337/diacare.28.7.1769] [PMID]

[7] Wilson PW, D'Agostino RB, Parise H, Sullivan L, Meigs JB. Metabolic syndrome as a precursor of cardiovascular disease and type 2 diabetes mellitus. Circulation. 2005; 112(20):3066-72. [DOI:10.1161/CIRCULATIONAHA.105.539528] [PMID]

[8] Ghorbanizad Shiran H, Abedini S, Rasulzadeh Aghdam S. The sociological explanation for prevention model of lifestyle diseases A grounded theory study. J Health Care. 2019; 21(4):293-307. [DOI:10.29252/jhc.21.4.293]

[9] Sarkar U, Piette JD, Gonzales R, Lessler D, Chew LD, Reilly B, et al. Preferences for self-management support: Findings from a survey of diabetes patients in safety-net health systems. Patient Educ Couns. 2008; 70(1):102-10. [DOI:10.1016/j.pec.2007.09.008] [PMID] [PMCID]

[10] Spires M, Delobelle P, Sanders D, Puoane T, Hoelzel P, Swart R. Diet-related non-communicable diseases in South Africa: Determinants and policy responses. South African Health Review. 2016; 2016(1):35-42. https://hdl.handle.net/10520/EJC189320

[11] Baum F, Fisher M. Why behavioural health promotion endures despite its failure to reduce health inequities. Sociol Health Illn. 2014; 36(2):213-25. [DOI:10.1111/1467-9566.12112] [PMID]

[12] Walker E, Stevens K, Persaud S. Promoting self-management among African Americans: An educational intervention. J Health Care Poor Underserved. 2010; 21(3 Suppl):169-86.[DOI:10.1353/ hpu.0.0363] [PMID]

[13] Zandinava H, Shafaei FS, Charandabi SM-A, Homayi SG, Mirghafourvand M. Effect of educational package on self-care behavior, quality of life, and blood glucose levels in pregnant women with gestational diabetes: A randomized controlled trial. Iran Red Crescent Med J. 2017; 19(4):(In Press). [DOI:10.5812/ ircmj.44317]

[14] Nguyen HQ, Donesky-Cuenco D, Wolpin S, Reinke LF, Benditt JO, Paul SM, et al. Randomized controlled trial of an internetbased versus face-to-face dyspnea self-management program for patients with chronic obstructive pulmonary disease: Pilot study. J Med Internet Res. 2008; 10(2):e9. [DOI:10.2196/jmir.990] [PMID] [PMCID]

[15] Heidari M, Fayazi S, Borsi S, Vafaizadeh M. Effect of Selfmanagement program on self-efficacy in patients with chronic obstructive pulmonary disease. Iran J Nurs. 2016; 29(99-100):4555. [DOI:10.29252/ijn.29.99.100.45]

[16] Abedi H, Salimi S, Feizi A, Safari Vaghasloo S. [Assessment of relationship between self efficacy and self-care in COPD Patients (Persian)]. Nurs Midwifery J. 2012; 10(1). http://unmf.umsu. ac.ir/article-1-740-fa.html
[17] Efraimsson EÖ, Hillervik C, Ehrenberg A. Effects of COPD self-care management education at a nurse-led primary health care clinic. Scand J Caring Sci. 2008; 22(2):178-85. [DOI:10.1111/ j.1471-6712.2007.00510.x] [PMID]

[18] Hamnes B, Mowinckel P, Kjeken I, Hagen KB. Effects of a one week multidisciplinary inpatient self-management program for patients with fibromyalgia: A randomized controlled trial. BMC Musculoskelet Disord. 2012; 26(13):189. [DOI:10.1186/1471-247413-189] [PMID] [PMCID]

[19] Barghi irani Z, Dehkhodaei S, Alipour A. The effectiveness of cognitive-behavioral therapy and treatment based on acceptance and commitment in adherence to treatment, illness perception and quality of life in hemophilic patients. Sci J Iran Blood Transfus Organ. 2019; 16 (4):289-99. https:/ / www.sid.ir/en/Journal/ ViewPaper.aspx?ID=770964

[20] Nolte S, Osborne RH. A systematic review of outcomes of chronic disease self-management interventions. Qual Life Res. 2013; 22(7):1805-16. [DOI:10.1007/s11136-012-0302-8] [PMID]

[21] Yousefy A, KhayamNekouei Z. Basis of Cognitive-Behavioral Trainings and its Applications in Recovery of Chronic Diseases. Iran J Med Educ. 2011; 10(5):792-800. http:// ijme.mui.ac.ir/browse.php?a_code=A-10-1108-1\&slc _ lang=en\&sid $=1 \&$ sw $=$ behavior

[22] Barkham M, Lutz W, Gastonguay LG. Bergin and garfield's handbook of psychotherapy and behavior change. Hoboken New Jersey: WILEY Blackwell; 2021. https:/ / www.wiley.com/ en-us/Bergin+and+Garfield \%27s+Handbook+of+Psychothera py+and+Behavior+Change $\% 2 C+7$ th+Edition-p-9781119536581

[23] Patten S, Williams J, Lavorato D, Wang J, Jetté N, Sajobi T, Bulloch A. Patterns of association of chronic medical conditions and major depression. Epidemiol Psychiatr Sci. 2018; 27(1):42-50. [DOI:10.1017/S204579601600072X] [PMID] [PMCID]

[24] Zhianfar L, Nadrian H, Asghari Jafarabadi M, Espahbodi F, Shaghaghi A. Effectiveness of a multifaceted educational intervention to enhance therapeutic regimen adherence and quality of life amongst Iranian hemodialysis patients: A randomized controlled trial (MEITRA Study). J Multidiscip Healthc. 2020; 13:361372. [DOI:10.2147/JMDH.S247128] [PMID] [PMCID]

[25] Cho L. Metabolic syndrome. Singapore Med J. 2011; 52(11):779. [DOI:10.3923/jms.2011.104.104]

[26] Rathnayake N, Alwis G, Lenora J, Lekamwasam S. Applicability of health promoting lifestyle profile-II for postmenopausal women in Sri Lanka; a validation study. Health Qual Life Outcomes. 2020; 18(1):122. [DOI:10.1186/s12955-020-01371-7] [PMID] [PMCID]

[27] Mohammadi Zeidi I, Pakpour Hajiagha A, Mohammadi Zeidi B. Reliability and validity of Persian version of the healthpromoting lifestyle profile. J Mazandaran Uni Med Sci. 2012; 21(1):102-13.

[28] Küçükberber N, Ozdilli K, Yorulmaz H. Evaluation of factors affecting healthy life style behaviors and quality of life in patients with heart disease. Anadolu Kardiyoloji Dergisi. 2011; 11(7):619-26. [DOI:10.5152/akd.2011.166] [PMID]

[29] Lu CH, Tang ST, Lei YX, Zhang MQ, Lin WQ, Ding SH, et al. Community-based interventions in hypertensive patients: A comparison of three health education strategies. BMC Public Health. 2015; 15:33. [DOI:10.1186/s12889-015-1401-6] [PMID] [PMCID] 
[30] Chodosh J, Morton SC, Mojica W, Maglione M, Suttorp MJ, Hilton L, et al. Meta-analysis: Chronic disease self-management programs for older adults. Ann Intern Med. 2005; 143(6):427-38 . [DOI:10.7326/0003-4819-143-6-200509200-00007] [PMID]

[31] Moattari M, Ghobadi A, Beigi P, Pishdad G. Impact of self management on metabolic control indicators of diabetes patients. J Diabetes Metab Disord. 2012; 11(1):6. [DOI:10.1186/2251-6581-11-6] [PMID] [PMCID]

[32] Zareipour MA, Sadeghi R, Movahed E, Jadgal MS. [The effect of educational intervention about lifestyle modification on knowledge, attitude and behavior of blood pressure control in patients with hypertension in Urmia (Persian)]. Nurs J Vulner. 2018; 5(15):1-13. http://njv.bpums.ac.ir/article1-827-fa.html

[33] Tandon VR, Sharma S, Mahajan A, Mahajan S. Effect of life-style modification on postmenopausal overweight and obese Indian women: A randomized controlled 24 weeks preliminary study. J Midlife Health. 2014; 5(1):23-8. [DOI:10.4103/0976-7800.127787] [PMID] [PMCID]

[34] Moradi, F, Shariat F, Mirzaeian K. [Identifying the effects of training of obesity prevention and weight management an the knowledge of clients to neighborhood health house in the Tehran city (Persian)]. Iran J Health Educ Health Promot. 2013; 1(1):33-40. http://journal.ihepsa.ir/article-1-42-en.html

[35] Sekendiza B, Altun Ö, Korkusuza F, Akınb S. Effects of Pilates exercise on trunk strength, endurance, and flexibility in sedentary adult females. J Bodywork Mov Ther. 2006; 11(4):318-26. [DOI:10.1016/j.jbmt.2006.12.002]

[36] Fischer J, Koszewski W, Jones G, Stanek-Krogstrand K. The use of interviewing to assess dietetic internship preceptors needs and perceptions. J Am Diet Assoc. 2006; 106(8):A48. [DOI:10.1016/j.jada.2006.05.144]

[37] Shrivastava SR, Shrivastava PS, Ramasamy J. Role of selfcare in management of diabetes mellitus. J Diabetes Metab Disord. 2013; 12(1):14. [DOI:10.1186/2251-6581-12-14] [PMID] [PMCID]

[38] Barker DJP. Developmental origins of chronic disease. Public health. 2012;126(3):185-9. [DOI:10.1016/j.puhe.2011.11.014] [PMID]

[39] Pinto PR, Paredes AC, Costa P, Carvalho M, Lopes M, Fernandes $\mathrm{S}$, et al. Effectiveness of two psychological interventions for pain management, emotional regulation and promotion of quality of life among adult Portuguese men with haemophilia (PSY-HaEMOPEQ): Study protocol for a singlecentre prospective randomised controlled trial. BMJ Open. 2017; 7(9):e016973. [DOI:10.1136/bmjopen-2017-016973] [PMID] [PMCID] 
This Page Intentionally Left Blank 